From The University of Texas M.D Anderson Cancer Center, Houston, TX; the University of Wisconsin Hospital and Clinics, Madison, WI; Cedars-Sinai Comprehensive Cancer Center, Beverly Hills, CA; Memorial Sloan-Kettering Cancer Center, New York, NY; Midwest Cancer Research Group, Skokie, IL; Florida Cancer Specialists, Fort Myers, FL; AstraZeneca Pharmaceuticals, Wilmington, DE; Vanderbilt-Ingram Cancer Center, Nashville, TN; Free University Medical Center, Amsterdam, the Netherlands; Thoraxklinik, Heidelberg, Germany; S. Luigi Gonzaga Hospital, Turin Italy; Hospital Germans Trias i Pujol, Barcelona, Spain; and AstraZeneca Pharmaceuticals, Alderley Park, United Kingdom.

Submitted July 24, 2003; accepted November 26, 2003

Supported by a grant from AstraZeneca, Wilmington, DE.

Authors' disclosures of potential conflicts of interest are found at the end of this article.

Address reprint requests to R.S. Herbst, MD, PhD, Department of Thoracic/Head and Neck Medical Oncology, University of Texas M.D. Anderson Cancer Center, 1515 Holcombe Blvd, Unit 432, Houston, TX 77030; e-mail: rherbst@mail.mdanderson.org.

(c) 2004 by American Society of Clinical Oncology

0732-183X/04/2205-785/\$20.00

DOI: $10.1200 / J C O .2004 .07 .215$

\title{
Gefitinib in Combination With Paclitaxel and Carboplatin in Advanced Non-Small-Cell Lung Cancer: A Phase III Trial-INTACT 2
}

Roy S. Herbst, Giuseppe Giaccone, Joan H. Schiller, Ronald B. Natale, Vincent Miller, Christian Manegold, Giorgio Scagliotti, Rafael Rosell, Ira Oliff, James A. Reeves, Michael K. Wolf, Annetta D. Krebs, Steven D. Averbuch, Judith S. Ochs, John Grous, Abderrahim Fandi, and David H. Johnson

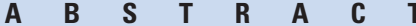

\section{Purpose}

Preclinical studies indicate that gefitinib (Iressa, ZD1839; AstraZeneca, Wilmington, DE), an orally active epidermal growth factor receptor tyrosine kinase inhibitor, may enhance antitumor efficacy of cytotoxics, and combination with paclitaxel and carboplatin had acceptable tolerability in a phase I trial. Gefitinib monotherapy demonstrated unparalleled antitumor activity for a biologic agent, with less toxicity than docetaxel, in phase II trials in refractory, advanced non-small-cell lung cancer (NSCLC). This phase III, randomized, placebo-controlled, double-blind trial evaluated gefitinib plus paclitaxel and carboplatin in chemotherapy-naive patients with advanced NSCLC.

\section{Patients and Methods}

Patients received paclitaxel $225 \mathrm{mg} / \mathrm{m}^{2}$ and carboplatin area under concentration/time curve of 6 $\mathrm{mg} / \mathrm{min} / \mathrm{mL}$ (day 1 every 3 weeks) plus gefitinib $500 \mathrm{mg} / \mathrm{d}$, gefitinib $250 \mathrm{mg} / \mathrm{d}$, or placebo. After a maximum of six cycles, daily gefitinib or placebo continued until disease progression. End points included overall survival, time to progression (TTP), response rate (RR), and safety evaluation.

\section{Results}

A total of 1,037 patients were recruited. Baseline demographic characteristics were well balanced. There was no difference in overall survival (median, 8.7, 9.8, and 9.9 months for gefitinib $500 \mathrm{mg} / \mathrm{d}, 250 \mathrm{mg} / \mathrm{d}$, and placebo, respectively; $P=.64$ ), TTP, or RR between arms. Expected dose-related diarrhea and skin toxicity were observed in gefitinib-treated patients, with no new significant/unexpected safety findings from combination with chemotherapy. Subset analysis of patients with adenocarcinoma who received $\geq 90$ days' chemotherapy demonstrated statistically significant prolonged survival, suggesting a gefitinib maintenance effect.

\section{Conclusion}

Gefitinib showed no added benefit in survival, TTP, or RR compared with standard chemotherapy alone. This large, placebo-controlled trial confirmed the favorable gefitinib safety profile observed in phase I and II monotherapy trials.

J Clin Oncol 22:785-794. (c) 2004 by American Society of Clinical Oncology

\section{INTRODUCTION}

Lung cancer is the most common cause of cancer death worldwide [1]. Current firstline chemotherapy options for patients with advanced non-small-cell lung cancer (NSCLC), such as the combination of a platinum-based agent with paclitaxel, gemcitabine, vinorelbine, or docetaxel, have substantial toxicity and seem to have reached a plateau in terms of efficacy. A randomized study by the Southwest Oncology Group showed that paclitaxel with carboplatin has similar efficacy to vinorelbine with cisplatin (median survival, 8 months for both regimens; 1 -year survival, $38 \%$ and $36 \%$, respectively) [2]. More recently, a study by the Eastern Cooperative Oncology Group found that four different platinum-based regimens had similar efficacies [3]. Clearly, improve- 
ment on these existing treatments for advanced NSCLC is needed, requiring the development of new agents with a different mechanism of action and an improved safety profile compared with chemotherapy.

The orally active epidermal growth factor receptor (EGFR) tyrosine kinase inhibitor gefitinib (Iressa, ZD1839; AstraZeneca, Wilmington, DE) blocks signal transduction pathways implicated in the proliferation and survival of cancer cells [4]. Four phase I studies have shown that gefitinib is generally well tolerated, with evidence of antitumor activity in a range of tumors including NSCLC [5-8]. Observations and pharmacokinetic data from these trials identified two doses for further study: gefitinib $250 \mathrm{mg} / \mathrm{d}$ is higher than the lowest dose at which clinical response was seen, and $500 \mathrm{mg} / \mathrm{d}$ is the highest dose level to be tolerated long-term by most patients. Two large phase II gefitinib monotherapy studies (Iressa Dose Evaluation in Advanced Lung Cancer [IDEAL] 1 and 2) in patients with pretreated advanced NSCLC further confirmed that this agent was generally well tolerated and produced durable, clinically significant antitumor activity (response rates for gefitinib $250 \mathrm{mg} / \mathrm{d}$ were $18.4 \%$ and $11.8 \%$ for IDEAL 1 and 2 , respectively), with improvement in disease-related symptoms observed in approximately $40 \%$ of symptomatic patients [9-11]. These response rates for patients receiving secondline and higher therapy were encouraging, particularly when considered in the context of the retrospective analysis by Massarelli et al [12], in which the response rate declined with each line of therapy (second line, 16.3\%; third line, $2.3 \%$ ). The most frequent drug-related adverse events observed in these two trials were skin rash and diarrhea, which were generally mild (grade 1 and 2). The results of randomized studies are awaited.

There is a strong rationale for combining gefitinib with standard chemotherapy agents. In preclinical studies, gefitinib enhanced the efficacy of cytotoxic agents against a range of human tumor xenografts, including lung cancer, regardless of EGFR expression [13,14]. A small phase I study of 24 patients with chemotherapy-naïve, advanced NSCLC showed that gefitinib in combination with paclitaxel and carboplatin was well tolerated, with no clinically significant pharmacokinetic drug-drug interactions [15]. Together, these preclinical data, data from gefitinib single-agent trials, and the favorable tolerability data from the phase I trial of this combination supported phase III investigation.

The Iressa NSCLC Trial Assessing Combination Treatment (INTACT) 2 was a randomized, placebo-controlled trial of paclitaxel and carboplatin with or without gefitinib in chemotherapy-naive patients with advanced NSCLC. This global multicenter study was conducted mainly (80\%) in the United States; INTACT 1, a parallel global trial that evaluated the combination of gefitinib with gemcitabine and cisplatin, was conducted mainly in Europe. The results of INTACT 1 are reported elsewhere [16]. The primary objective of INTACT 2 was to determine overall survival, and the secondary end point was time to progression. Additional end points included objective response rate, disease-related symptom and quality-of-life outcomes, and adverse-event profiling.

\section{PATIENTS AND METHODS}

\section{Eligibility Criteria}

Patients were assessed by physical examination and history to ensure that eligibility criteria were met. Entry criteria included histologically confirmed NSCLC (cytologic specimens obtained by brushing, washing, or needle aspiration of a defined lesion were acceptable), unresectable stage III or IV disease, no prior chemotherapy, age $\geq 18$ years, and performance status 0 to 2 . Exclusion criteria included the presence of mixed NSCLC or small-cell lung cancer, brain metastases that were newly diagnosed or had not been treated with surgery or radiation, previously treated CNS metastases or spinal-cord compression in the absence of clinically stable disease, less than 2 weeks since radiotherapy, unresolved toxicity from prior radiotherapy or incomplete healing from

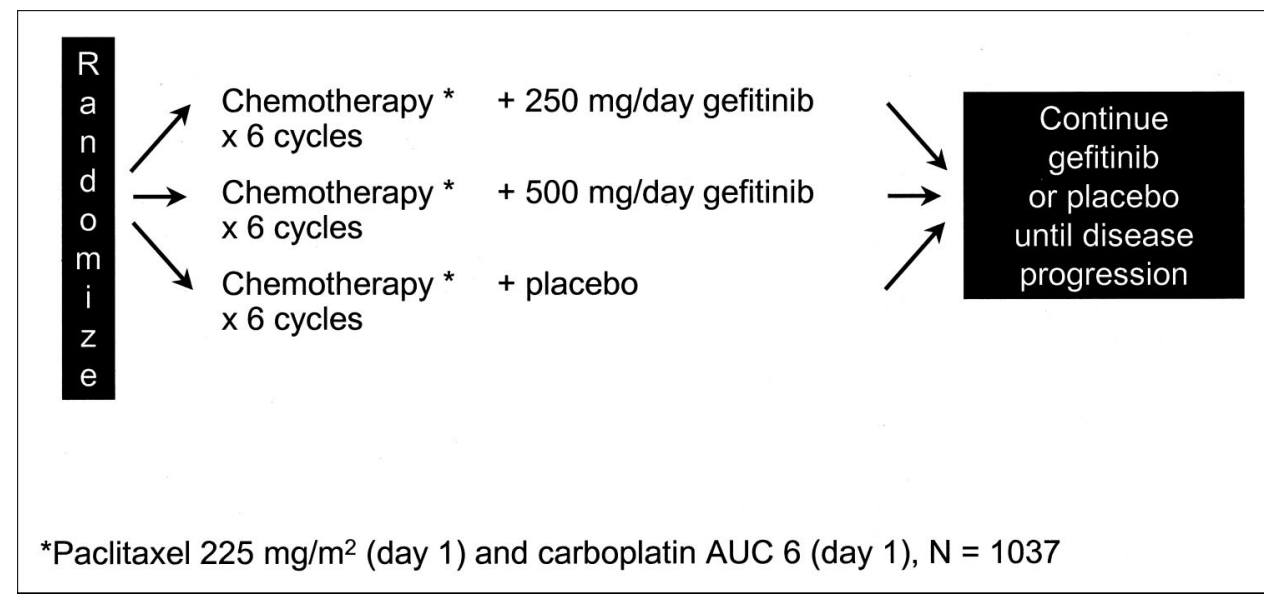

Fig 1. INTACT 2 trial schema. AUC area under concentration-time curve. 


\begin{tabular}{|c|c|c|c|}
\hline & $\begin{array}{c}\text { Gefitinib } 500 \mathrm{mg} / \mathrm{d} \\
(\mathrm{n}=347)\end{array}$ & $\begin{array}{l}\text { Gefitinib } 250 \mathrm{mg} / \mathrm{d} \\
\quad(\mathrm{n}=345)\end{array}$ & $\begin{array}{c}\text { Placebo } \\
(\mathrm{n}=345)\end{array}$ \\
\hline \multicolumn{4}{|l|}{ Sex, \% } \\
\hline Female & 40.1 & 42.3 & 38.6 \\
\hline Male & 59.9 & 57.7 & 61.4 \\
\hline \multicolumn{4}{|l|}{ Age, years } \\
\hline Median & 62 & 61 & 63 \\
\hline Range & $26-82$ & $27-86$ & $31-85$ \\
\hline \multicolumn{4}{|l|}{ Disease stage, \%* } \\
\hline IIla & 2.6 & 2.3 & 3.8 \\
\hline $\mathrm{IIlb}$ & 15.3 & 16.2 & 17.1 \\
\hline Without pleural effusion & 3.5 & 3.2 & 5.2 \\
\hline With pleural effusion & 11.8 & 13.0 & 11.9 \\
\hline IV & 81.8 & 81.2 & 78.3 \\
\hline \multicolumn{4}{|l|}{ WHO performance status, \%* } \\
\hline 0 & 34.6 & 33.0 & 38.6 \\
\hline 1 & 51.9 & 56.5 & 51.9 \\
\hline 2 & 13.3 & 10.4 & 9.3 \\
\hline \multicolumn{4}{|c|}{ Weight loss in previous 6 months, \%* } \\
\hline$\leq 5 \%$ & 59.1 & 62.6 & 60.9 \\
\hline$>5 \%$ & 39.5 & 37.1 & 38.3 \\
\hline \multicolumn{4}{|l|}{ Disease measurability, \%* } \\
\hline Measurable & 93.9 & 91.3 & 88.4 \\
\hline Nonmeasurable & 5.8 & 7.8 & 11.0 \\
\hline \multicolumn{4}{|l|}{ Histology, \%* } \\
\hline Squamous & 16.7 & 20.3 & 19.4 \\
\hline Adenocarcinoma & 57.9 & 55.7 & 51.9 \\
\hline Adenosquamous & 2.9 & 2.3 & 1.7 \\
\hline Bronchoalveolar & 2.9 & 2.9 & 3.2 \\
\hline Unspecified NSCLC & 11.5 & 9.6 & 11.3 \\
\hline Large cell & 7.2 & 8.7 & 11.0 \\
\hline \multicolumn{4}{|l|}{ Race, \% } \\
\hline White & 88.5 & 90.4 & 91.9 \\
\hline Black & 7.5 & 4.1 & 5.2 \\
\hline Other & 4.0 & 5.5 & 2.9 \\
\hline
\end{tabular}

surgery, evidence of severe systemic disease, greater than trace blood or protein on repeat urinalysis, absolute neutrophil count less than $2,000 / \mu \mathrm{L}$, WBCs less than $4,000 / \mu \mathrm{L}$, platelets less than $100,000 / \mu \mathrm{L}$, serum bilirubin greater than 1.25 times the upper limit of reference range (ULRR); ALT or AST greater than 2.5 times ULRR ( $>$ five times ULRR in the presence of liver metastases), serum creatinine greater than 1.5 times ULRR, pregnancy or breast-feeding, and hypersensitivity to mannitol, corticosteroids, $\mathrm{H}_{2}$-antagonists, antihistamines, or agents formulated with polyoxyethylated castor oil.

All patients gave written informed consent and approval was obtained from the ethics committee at each trial center. The study followed the Declaration of Helsinki [17] and good clinical practice guidelines.

\section{Trial Design}

All patients received chemotherapy (intravenous paclitaxel $225 \mathrm{mg} / \mathrm{m}^{2}$ over 3 hours on day 1 of a 3-week cycle immediately followed by intravenous carboplatin area under concentration/ time curve [18] of $6 \mathrm{mg} / \mathrm{min} / \mathrm{mL}$ over 15 to 30 minutes on day 1) and were randomized to receive either oral gefitinib at 250 or 500 mg/d or daily oral placebo (Fig 1). Chemotherapy was continued for six cycles in the absence of disease progression. Thereafter, patients were maintained on gefitinib or placebo until disease progression or drug intolerance.

Before randomization, patients were stratified according to weight loss in the previous 6 months ( $\leq 5 \% v>5 \%)$, disease stage (III $v$ IV), performance status (0 or $1 v 2$ ), and the presence of measurable disease (yes $v$ no).

\section{Statistical Analysis}

The trial was governed by a steering committee of INTACT principal investigators. The ongoing safety review and interim analyses were conducted by an Independent Data Monitoring Committee. The first interim analysis was for safety, to rule out a detrimental survival effect for gefitinib early in the trial.

Gefitinib was compared with placebo on an intent-to-treat basis with respect to overall survival. The study was designed to have $90 \%$ power for a two-sided overall significance level test of the hypothesis that gefitinib increases survival relative to placebo, given a hazard ratio of 1.33 . Assuming a 1 -year survival rate of $30 \%$ in the placebo arm, in line with the data available at the time of 
protocol writing, this hazard ratio equates to an increase in median survival of 2.3 months for both gefitinib arms. The final analysis of overall survival was planned to include 750 events. Based on the study design assumptions, 1,029 patients were required.

At the final analysis, an adaptive survival analysis procedure was used that tested either for a positive or negative gefitinib dose-response relationship, based on prospective criteria applied to the observed data. A survival trend test (global ordered log-rank [GOLrank] test), in which the hypothesis was no effect versus the specific ordering of placebo, gefitinib $250 \mathrm{mg} / \mathrm{d}$, and gefitinib 500 $\mathrm{mg} / \mathrm{d}$, was used for a positive dose-response, whereas pairwise log-rank tests would be used for a mixed dose-response [19]. To preserve an overall two-sided 5\% significance level, and to account for the use of a survival trend test at the second interim analysis, simulations with the adaptive procedure were used to calculate a nominal significance level of $4.4 \%$ for the final analysis. According to prospective criteria for the adaptive procedure, the final analysis used a survival trend test to compare survival between the treatment arms.

A posthoc multivariate analysis with eight prespecified prognostic factors at trial entry (disease stage III $v$ IV; performance status 0 or $1 v 2$; weight loss in prior 6 months $\leq 5 \% v>5 \%$; sex; histology; presence or absence of metastases to bone, liver, or brain) was performed to assess which variables were predictive of improved survival.

In a posthoc subgroup analysis, stratification and prognostic factors (disease stage III $v$ IV; performance status 0 or $1 v 2$; weight loss in prior 6 months $\leq 5 \% v>5 \%$; presence or absence of metastases to bone, liver, or brain) and subgroups of sex, time on chemotherapy, and histology were analyzed in a univariate model. An unadjusted Cox proportional hazard test was applied to the overall survival data for each subgroup to estimate the hazard ratio and $95 \%$ CI for the treatment comparisons of gefitinib 250 or 500 $\mathrm{mg} / \mathrm{d}$ versus placebo.

\section{Assessments}

Overall survival and time to progression were assessed from the date of randomization to the date of death (any cause) and the date of objective disease progression (death was considered a progression event in patients who died before disease progression), respectively. Patients without documented death or objective progression at the time of the final analysis were censored at the date last known to be alive or their last objective tumor assessment, respectively.

Tumor response was evaluated according to Response Evaluation Criteria In Solid Tumors, the revised version of the International Union Against Cancer/WHO criteria [20].

During the trial, and for 30 days after the last dose of gefitinib or placebo, patients were monitored for adverse events, graded according to the National Cancer Institute Common Toxicity Criteria (CTC) version 2.0. Hematology and biochemistry assessments were performed $\leq 7$ days before the date of randomization and at each clinic visit. Analysis of other end points, such as symptom improvement rate, quality of life, and correlation of EGFR with survival, is ongoing and will be reported separately.

\section{RESULTS}

\section{Patients}

In total, 1,037 patients were recruited between May 2000 and April 2001, approximately $80 \%$ of whom were in the United States. The baseline characteristics of the patients were similar in each of the three treatment groups (Table 1). Most patients (approximately 80\%) had metastatic stage IV disease, and more than $50 \%$ of patients in each group had adenocarcinoma. Approximately 20\% of patients in each of the treatment groups are confirmed to have continued receiving chemotherapy after withdrawal from the study.

\section{Efficacy}

At each interim analysis, the Independent Data Monitoring Committee made recommendations to continue the trial. A total of 725 events $(246,232$, and 247 events for gefitinib $500 \mathrm{mg} / \mathrm{d}$, gefitinib $250 \mathrm{mg} / \mathrm{d}$, and placebo, respectively) were observed for survival and 637 events $(178,215$, and 244 events, respectively) for time to progression, with a minimum follow-up of 12 months for survival and 6 months for all other end points.

At the final analysis, neither dose of gefitinib improved overall survival when added to paclitaxel and carboplatin compared with paclitaxel and carboplatin plus placebo (GOLrank $P=.6385$ ). Median survival was $8.7,9.8$, and 9.9 months in the gefitinib $500 \mathrm{mg} / \mathrm{d}$, gefitinib $250 \mathrm{mg} / \mathrm{d}$, and placebo arms, respectively (Fig 2A). The 1-year survival

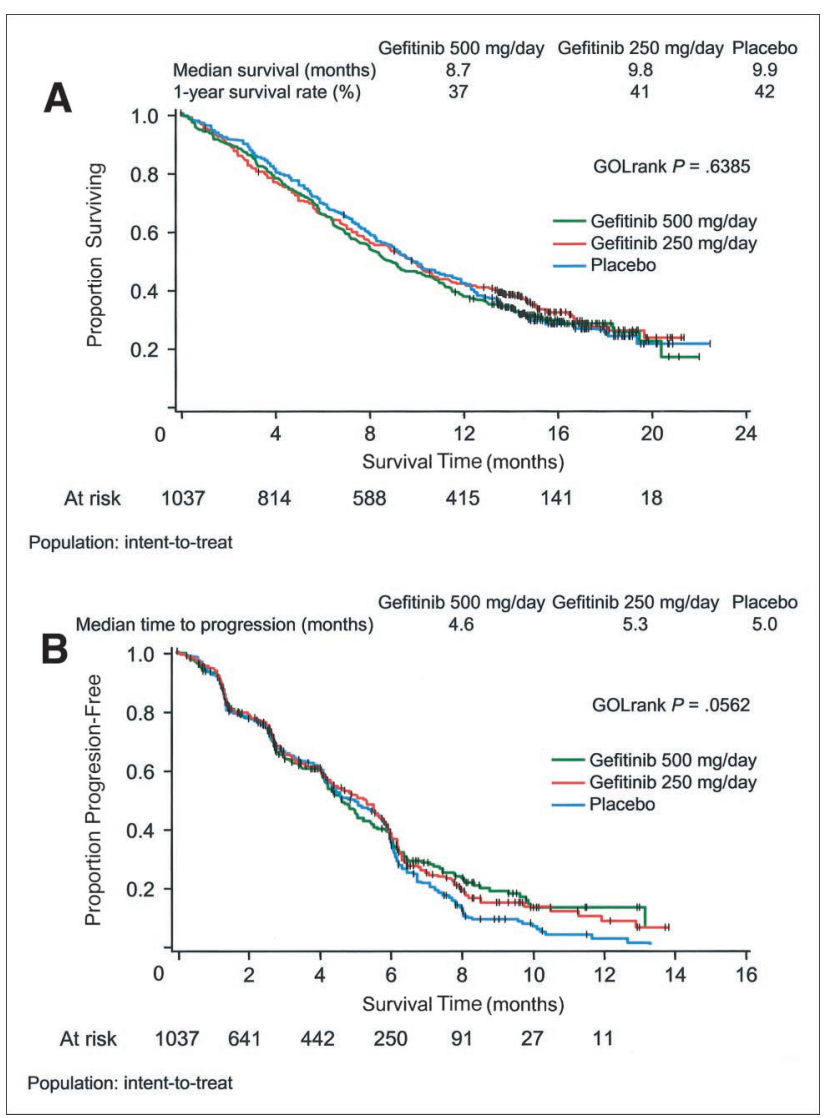

Fig 2. Kaplan-Meier estimates of (A) overall survival and (B) time to progression. GOLrank, global ordered log-rank test. 


\begin{tabular}{|c|c|c|c|c|c|c|}
\hline \multirow[b]{2}{*}{ Factor } & \multicolumn{3}{|c|}{ Placebo v Gefitinib 250 mg/d } & \multicolumn{3}{|c|}{ Placebo v Gefitinib 500 mg/d } \\
\hline & Hazard Ratio* & $95 \% \mathrm{Cl}$ & $P$ & Hazard Ratio* & $95 \% \mathrm{Cl}$ & $P$ \\
\hline \multicolumn{7}{|l|}{ Sex } \\
\hline Male & 1.074 & 0.858 to 1.345 & .531 & 1.112 & 0.891 to 1.388 & .349 \\
\hline Female & 0.945 & 0.700 to 1.277 & .714 & 0.761 & 0.567 to 1.023 & .070 \\
\hline \multicolumn{7}{|l|}{ Disease stage } \\
\hline III & 0.986 & 0.651 to 1.492 & .947 & 1.312 & 0.845 to 2.036 & .226 \\
\hline IV & 1.060 & 0.868 to 1.294 & .571 & 0.917 & 0.754 to 1.114 & .381 \\
\hline \multicolumn{7}{|l|}{ Performance status } \\
\hline 0 or 1 & 1.047 & 0.864 to 1.269 & .641 & 1.003 & 0.827 to 1.215 & .980 \\
\hline 2 & 0.972 & 0.587 to 1.610 & .911 & 0.903 & 0.567 to 1.439 & .668 \\
\hline \multicolumn{7}{|c|}{ Weight loss in the 6 months prior to entry } \\
\hline$\leq 5 \%$ & 1.034 & 0.814 to 1.314 & .786 & 0.974 & 0.767 to 1.237 & .829 \\
\hline$>5 \%$ & 1.012 & 0.771 to 1.328 & .933 & 0.951 & 0.728 to 1.243 & .714 \\
\hline \multicolumn{7}{|l|}{ Histology type } \\
\hline $\begin{array}{l}\text { Adenocarcinoma, including } \\
\text { bronchoalveolar carcinoma }\end{array}$ & 1.156 & 0.905 to 1.476 & .247 & 1.030 & 0.812 to 1.306 & .808 \\
\hline Other & 0.919 & 0.642 to 1.315 & .642 & 0.738 & 0.523 to 1.042 & .084 \\
\hline \multicolumn{7}{|l|}{ Metastases } \\
\hline Bone & 0.835 & 0.595 to 1.171 & .296 & 0.946 & 0.685 to 1.307 & .737 \\
\hline Liver & 1.028 & 0.703 to 1.503 & .887 & 0.899 & 0.617 to 1.311 & .580 \\
\hline Brain & 1.727 & 0.727 to 4.104 & .216 & 0.673 & 0.335 to 1.352 & .266 \\
\hline
\end{tabular}

rates were $37 \%, 41 \%$, and $42 \%$, respectively. Similarly, there was no statistically significant difference between the three groups in median time to progression $(4.6,5.3$, and 5.0 months, respectively; GOLrank $P=.0562$; Fig 2B).

In the posthoc multivariate analysis, performance status of 2, weight loss, and bone and liver metastases were significant $(P<.05)$ predictors of worse survival outcome. Survival differences were also seen for sex and brain metastases. For the posthoc univariate analysis, generally similar patterns were observed in each of the subgroup analyses, showing no overall difference between treatment groups $(P>.05$, not

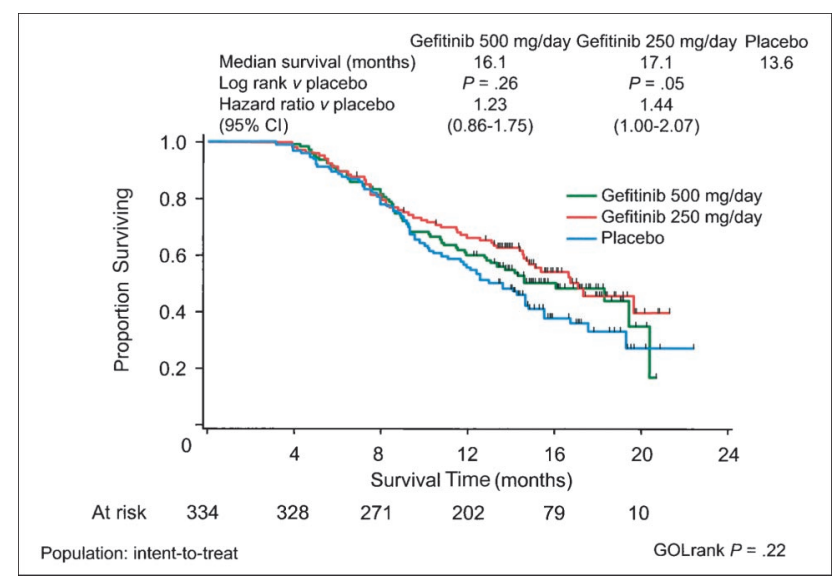

Fig 3. Subset analysis of patients with adenocarcinoma who received $\geq 90$ days of chemotherapy. GOLrank, global ordered log-rank test. significant; Table 2). There was no survival advantage in any of the subgroups when gefitinib at any dose was added to chemotherapy. However, there was a trend toward improved survival in the subgroup of patients with adenocarcinoma who had received chemotherapy for $\geq 90$ days (patients would have received at least the median number of chemotherapy cycles) in the gefitinib $250 \mathrm{mg} / \mathrm{d}$ arm $(P=.05$; Fig 3), suggesting a possible effect of gefitinib monotherapy as maintenance therapy. Although this trend continued for other subgroups (Table 3 ), the numbers were too small to yield statistical significance.

Complete responses were rare, observed in $0.6 \%, 2.6 \%$, and $1.2 \%$ of patients in the gefitinib $500 \mathrm{mg} / \mathrm{d}$, gefitinib 250 $\mathrm{mg} / \mathrm{d}$, and placebo arms, respectively, and overall response rates were $30.0 \%, 30.4 \%$, and $28.7 \%$, respectively, demonstrating no statistically significant efficacy difference between treatment arms.

\section{Duration of Therapy, Dose Adherence, and Dose-Intensity}

Patients receiving gefitinib $250 \mathrm{mg} / \mathrm{d}$ or placebo had a longer duration of therapy than those receiving gefitinib $500 \mathrm{mg} / \mathrm{d}$ (Table 4). Similarly, the number of gefitinib dose interruptions and reductions was highest in the gefitinib $500 \mathrm{mg} / \mathrm{d}$ arm and similar in the gefitinib $250 \mathrm{mg} / \mathrm{d}$ and placebo arms. There was a high overall adherence to gefitinib, and the median dose-intensity for both paclitaxel and carboplatin was similar in all treatment arms (Table 4). 


\begin{tabular}{|c|c|c|c|c|}
\hline \multirow[b]{2}{*}{ Chemotherapy } & \multirow{2}{*}{$\begin{array}{c}\text { No. of } \\
\text { Patients }\end{array}$} & \multicolumn{3}{|c|}{ Median Survival (months) } \\
\hline & & Gefitinib 500 mg/d & Gefitinib $250 \mathrm{mg} / \mathrm{d}$ & Placebo \\
\hline$\geq 90$ days & 599 & 14.1 & 14.9 & 13.0 \\
\hline$\geq 90$ days + adenocarcinoma & 334 & 16.1 & 17.1 & 13.6 \\
\hline$\geq 90$ days + stage IV disease & 458 & 12.0 & 15.1 & 12.6 \\
\hline$\geq 90$ days + adenocarcinoma + stage IV disease & 260 & 13.7 & 19.7 & 12.5 \\
\hline
\end{tabular}

\section{Safety and Tolerability}

Most adverse events occurred during combination treatment and many were attributed to chemotherapy. The safety profile of gefitinib from the monotherapy phase of the trial was similar to that seen in the phase II program. The most common adverse events were gastrointestinal, skin-related, and hematologic in nature. The incidence of acne and rash by grade is shown in Table 5; most of these events were mild (grade 1 or 2). Hematologic adverse events occurred with similar incidence in all three treatment groups, consistent with the toxicity profile of chemotherapy. Gefitinib did not seem to exacerbate these toxicities. Interstitial lung disease (ILD)-type events were experienced by $1.5 \%, 2.1 \%$ and $0.9 \%$ of patients in the gefitinib 500 $\mathrm{mg} / \mathrm{d}$, gefitinib $250 \mathrm{mg} / \mathrm{d}$, and placebo arms, respectively, and the incidence of dyspnea and other pulmonary adverse events such as cough and pneumonia were generally similar across treatment arms (Table 6). For those adverse events considered to be drug-related (possibly related to gefitinib or placebo), there was a gefitinib dose-response relationship for skin and gastrointestinal events (Table 7). The most frequent grade 3 or 4 drug-related adverse events were diarrhea and rash, which occurred at a higher incidence in the gefitinib $500 \mathrm{mg} / \mathrm{d}$ arm than in the gefitinib $250 \mathrm{mg} / \mathrm{d}$ or placebo arms (Table 7). Statistical analysis of prespecified adverse events during the chemotherapy phase revealed no difference between treatment arms except for diarrhea $(P<$ .0001 for gefitinib $500 \mathrm{mg} / \mathrm{d} v$ gefitinib $250 \mathrm{mg} / \mathrm{d}$ or placebo;
$P=.0011$ for gefitinib $250 \mathrm{mg} / \mathrm{d} v$ placebo), defined skin events $(P=.0001$ for gefitinib $500 \mathrm{mg} / \mathrm{d} v$ gefitinib 250 $\mathrm{mg} / \mathrm{d} ; P<.0001$ for gefitinib $500 \mathrm{mg} / \mathrm{d}$ or gefitinib 250 $\mathrm{mg} / \mathrm{d} v$ placebo), and CTC grade 3 and 4 infectious events (predominantly sepsis and febrile neutropenia, rather than any specific or localized infections; $P=$ not significant for gefitinib $500 \mathrm{mg} / \mathrm{d} v$ gefitinib $250 \mathrm{mg} / \mathrm{d} ; P=.0099$ for gefitinib $500 \mathrm{mg} / \mathrm{d} v$ placebo; $P=.022$ for gefitinib $250 \mathrm{mg} / \mathrm{d} v$ placebo). No adjustments were made to the $P$ values in these analyses to take account of the multiple comparisons.

Posthoc analyses were performed to assess the survival status for patients with specific rash and diarrhea events. The first analysis was performed in a subgroup of patients with any CTC grade event with Coding Symbols for a Thesaurus of Adverse Reaction Terms of acne, rash, or dry skin. The second analysis was performed in a subgroup of patients with CTC grade $\geq 2$ events (specifically acne, rash, dry skin, and diarrhea). Neither posthoc analysis showed a difference in overall survival between the three treatment groups.

Only six deaths were considered to be drug-related: three patients in the gefitinib $500 \mathrm{mg} / \mathrm{d}$ arm (sudden death, intestinal obstruction, and dehydration plus kidney failure); one in the gefitinib $250 \mathrm{mg} / \mathrm{d}$ arm (pulmonary embolus); and two in the placebo arm (sepsis and cerebral vascular accident). The type of adverse events leading to withdrawal were similar in all three treatment groups, the most common being diarrhea. Fewer patients discontinued therapy because of adverse events (any cause) in the ge-

\begin{tabular}{|c|c|c|c|}
\hline & $\begin{array}{c}\text { Gefitinib } 500 \mathrm{mg} / \mathrm{d} \\
\quad(n=342)\end{array}$ & $\begin{array}{c}\text { Gefitinib } 250 \mathrm{mg} / \mathrm{d} \\
\quad(\mathrm{n}=342)\end{array}$ & $\begin{array}{l}\text { Placebo } \\
(\mathrm{n}=341)\end{array}$ \\
\hline \multicolumn{4}{|l|}{ Gefitinib } \\
\hline Median duration of gefitinib/placebo therapy, days & 99 & 129 & 138 \\
\hline Dose interruption, \%* & 55.0 & 26.3 & 20.5 \\
\hline Dose reduction, \%* & 28.9 & 8.2 & 3.2 \\
\hline Median dose adherence, \% & 92.2 & 98.9 & 99.5 \\
\hline \multicolumn{4}{|l|}{ Chemotherapy } \\
\hline Median no. of chemotherapy cycles & 5 & 5 & 6 \\
\hline Paclitaxel median dose-intensity, \% & 95.3 & 96.0 & 96.1 \\
\hline Carboplatin median dose-intensity, \% & 85.8 & 87.4 & 88.5 \\
\hline
\end{tabular}




\begin{tabular}{|cccc|}
\hline \multicolumn{4}{c}{ Table 5. Skin Reactions by Grade } \\
\hline & \multicolumn{3}{c|}{ \% of Patients } \\
\cline { 2 - 4 } & $\begin{array}{c}\text { Gefitinib 500 mg/d } \\
(\mathrm{n}=342)\end{array}$ & $\begin{array}{c}\text { Gefitinib 250 mg/d } \\
(\mathrm{n}=342)\end{array}$ & $\begin{array}{c}\text { Placebo } \\
(\mathrm{n}=341)\end{array}$ \\
\hline Rash & & & \\
None & 26.0 & 40.0 & 55.1 \\
Grade 1 & 32.2 & 40.4 & 32.0 \\
Grade 2 & 29.8 & 15.8 & 11.4 \\
Grade 3 & 11.1 & 3.8 & 1.5 \\
Grade 4 & 0.9 & 0 & 0 \\
Acne & & & \\
None & 73.1 & 79.0 & 90.6 \\
Grade 1 & 10.5 & 14.0 & 7.3 \\
Grade 2 & 11.4 & 6.1 & 2.1 \\
Grade 3 & 4.4 & 0.9 & 0 \\
Grade 4 & 0.6 & 0 & 0 \\
Rash or acne & & & \\
None & 20.8 & 33.6 & 51.9 \\
Grade 1 & 33.0 & 42.1 & 33.7 \\
Grade 2 & 31.6 & 19.6 & 12.9 \\
Grade 3 & 13.7 & 4.7 & 1.5 \\
Grade 4 & 0.9 & 0 & 0 \\
\hline & & & \\
\hline
\end{tabular}

fitinib $250 \mathrm{mg} / \mathrm{d}$ and placebo groups (10.5\% and 7.9\%, respectively) than in the gefitinib $500 \mathrm{mg} / \mathrm{d}$ group (22.5\%).

\section{DISCUSSION}

This large, randomized, placebo-controlled trial examined the efficacy and safety of gefitinib in combination with paclitaxel and carboplatin for the front-line therapy of advanced NSCLC. The data from 1,037 patients demonstrate that combination of conventional chemotherapy with gefitinib did not improve patient survival, disease-free survival, or response rate compared with chemotherapy given alone. Results with gefitinib $250 \mathrm{mg} / \mathrm{d}$ were similar to those in the placebo arm, whereas gefitinib $500 \mathrm{mg} / \mathrm{d}$ tended toward a worse outcome, although it was not statistically different from placebo. Median survival was 8.7, 9.8, and 9.9 months in the gefitinib $500 \mathrm{mg} / \mathrm{d}$, gefitinib $250 \mathrm{mg} / \mathrm{d}$, and placebo arms, respectively. These results are disappointing and surprising in view of recent results obtained with the phase II studies of single-agent gefitinib in recur-

\begin{tabular}{|lccc|}
\hline \multicolumn{4}{c|}{ Table 6. Pulmonary Adverse Events } \\
\hline & $\begin{array}{c}\text { Gefitinib 500 mg/ } \\
\mathrm{d}(\mathrm{n}=342)\end{array}$ & $\begin{array}{c}\text { Gefitinib 250 mg/d } \\
(\mathrm{n}=342)\end{array}$ & $\begin{array}{c}\text { Placebo } \\
(\mathrm{n}=341)\end{array}$ \\
\hline Dyspnea, \% & 34.2 & 36.5 & 32.6 \\
Cough, \% & 26.6 & 27.8 & 24.3 \\
Pneumonia, \% & 8.5 & 8.2 & 8.5 \\
ILD event, $\mathrm{n}$ & 5 & 7 & 3 \\
\hline
\end{tabular}

Abbreviation: ILD, interstitial lung disease. rent NSCLC (IDEAL 1 and 2). Tumor response rates of $11.8 \%$ to $18.4 \%$ and a clinically meaningful symptom improvement of approximately $40 \%$ were reported $[9,11]$. However, in contrast to the current study in chemotherapynaive patients, the phase II studies recruited patients with recurrent or refractory disease after prior chemotherapy regimens that included platinum. It has yet to be determined whether this difference in patient population alone influenced the lack of additional response seen in our study. It could be speculated that recurrent NSCLC uses EGFR ligands as potential survival factors after platinum-based chemotherapy, as it has been reported that EGF stimulates production of the survival factor vascular endothelial growth factor [21,22]. Recent results show that two phase III trials of first-line erlotinib in combination with standard chemotherapy in patients with metastatic NSCLC did not meet their primary end point of improving overall survival.

The current results are also surprising given the striking results reported for gefitinib in combination with chemotherapy in animal models $[13,14]$. Given our findings, the relevance of animal models to human cancers should be carefully examined, as experimental preclinical results frequently do not translate to the clinic. One factor is the lower doses of chemotherapy agents often used in animal models to observe a synergy with biologic therapies. We used the maximum therapeutic dose of carboplatin and paclitaxel in this human trial, which might have negated this effect. Another limitation is related to tumor implantation in the animal models. Rather than orthotopic tumors, most researchers use subcutaneous ectopic tumor implants, which are devoid of interaction with the true microenvironment of lung cells, and this could specifically alter tumor growth in vivo and perhaps the response to these agents $[23,24]$. Additionally, many of these cells are implanted only a short time before the start of therapy, which is, of course, much different from the human situation. These unrealistic growth patterns may also alter the response to therapy. Interestingly, the subset analysis of adenocarcinoma patients who received $\geq 90$ days of chemotherapy suggests that patients receiving gefitinib $250 \mathrm{mg} / \mathrm{d}$ who completed therapy had some long-term survival benefits, indicating that gefitinib might be effective as a cytostatic agent in humans, maintaining tumor regression after chemotherapy. This may be due to the ability of gefitinib to block EGFR-dependent survival pathways or possibly due to enhancement of apoptosis. However, this was not seen to the same significant extent in INTACT 1 [16]. These analyses were done posthoc and suffer from selection factors. Furthermore, as many analyses were performed for different subgroups, it is possible that observed effects could have appeared by chance alone. Perhaps the best use of gefitinib in vivo will be in sequence with chemotherapy. This hypothesis can be tested in randomized trials, and plans are underway to initiate such trials. Several options exist, in- 


\begin{tabular}{|c|c|c|c|c|c|c|}
\hline & \multicolumn{6}{|c|}{$\%$ of Patients } \\
\hline & \multicolumn{2}{|c|}{ Gefitinib 500 mg/d ( $n=342)$} & \multicolumn{2}{|c|}{ Gefitinib $250 \mathrm{mg} / \mathrm{d}(\mathrm{n}=342)$} & \multicolumn{2}{|c|}{ Placebo $(n=341)$} \\
\hline & All & Grade 3 or 4 & All & Grade 3 or 4 & All & Grade 3 or 4 \\
\hline Diarrhea & 69.3 & 25.4 & 58.2 & 9.9 & 29.3 & 2.9 \\
\hline Rash & 67.3 & 11.7 & 54.4 & 3.2 & 37.5 & 1.5 \\
\hline Acne & 26.3 & 5.0 & 19.9 & 0.9 & 7.3 & 0 \\
\hline Dry skin & 25.7 & 1.5 & 15.2 & 0.3 & 4.4 & 0 \\
\hline Pruritus & 20.5 & 1.8 & 15.2 & 0.6 & 12.6 & 0.3 \\
\hline Nausea & 18.7 & 4.1 & 19.3 & 1.8 & 14.7 & 2.1 \\
\hline Vomiting & 12.9 & 2.9 & 11.7 & 2.0 & 9.4 & 2.3 \\
\hline Anorexia & 11.7 & 0.6 & 7.0 & 0.6 & 6.2 & 0.3 \\
\hline Asthenia & 11.1 & 2.3 & 13.5 & 0.3 & 10.3 & 1.2 \\
\hline Dehydration & 9.9 & 5.0 & 3.8 & 1.8 & 2.9 & 1.8 \\
\hline Neutropenia & 7.0 & 6.1 & 7.9 & 6.7 & 5.9 & 5.9 \\
\hline Anemia & 6.7 & 1.2 & 6.4 & 0.6 & 2.6 & 0.6 \\
\hline Neuropathy & 4.1 & 0.9 & 5.3 & 0.3 & 5.9 & 0.9 \\
\hline Leukopenia & 3.2 & 2.3 & 5.3 & 2.0 & 3.8 & 2.1 \\
\hline Conjunctivitis & 6.4 & 0.6 & 5.3 & 0 & 3.2 & 0 \\
\hline Alopecia & 1.5 & 0 & 4.7 & 0 & 4.7 & 0 \\
\hline Dyspnea & 0.9 & 0.3 & 0.9 & 0.6 & 1.5 & 0.3 \\
\hline
\end{tabular}

cluding first-line gefitinib followed by chemotherapy, gefitinib maintenance therapy after response to chemotherapy or radiotherapy, or adjuvant gefitinib after surgery or radiotherapy for early-stage disease.

This trial was the first placebo-controlled study to address the question of gefitinib safety, and it confirms the safety profile from phase I and II monotherapy trials. Diarrhea and skin toxicity were milder and less frequently reported in the $250 \mathrm{mg} / \mathrm{d}$ dose group than in the $500 \mathrm{mg} / \mathrm{d}$ group. The frequency of other gastrointestinal side effects was relatively low and similar to the placebo arm. With the exception of mild-to-moderate diarrhea and skin-related events, the gefitinib $250 \mathrm{mg} / \mathrm{d}$ arm exhibited a safety profile similar to the placebo arm. Recently, ILD has been reported for four of 18 patients treated with gefitinib for NSCLC, two of whom died [25]. The same incidence was not seen in this randomized controlled study, in which the incidence of ILD-type events was similar in all treatment arms. The favorable tolerability of gefitinib is further supported by the high overall dose adherence. In addition, no change of the expected chemotherapy-related toxicity was observed in the gefitinib-treated arms. Other than dose-response effects, no predisposition factors for gefitinib toxicity were identified, and it can be concluded that gefitinib $250 \mathrm{mg} / \mathrm{d}$ has an acceptable safety profile when administered alone or in combination with chemotherapy. Similar results were seen in the INTACT 1 study [16].

Another possible explanation for the lack of a survival difference seen in this study is that patients were not selected on entry for sensitivity to the study agent (in large part because a sensitivity assay does not yet exist). High expression of EGFR has been associated with lower relapsefree and overall survival rates in several malignancies in retrospective studies [26]. However, sensitivity to antiEGFR therapy does not seem to be correlated with expression of this receptor [27], and conflicting results regarding the relationship between receptor expression and the efficacy of gefitinib have been reported [14,28-31]. It is possible that only patients with upregulated signal transduction pathways along the EGFR axis, such as the Akt pathway, might benefit. Patient selection was important in the use of trastuzumab in metastatic breast cancer, where a positive result with chemotherapy was seen in the subgroup of patients who had significant overexpression of the target [32].

At this time there is no standard method to detect EGFR, HER2, and their phosphorylated forms. Evaluation of the biology of NSCLC tumors treated with gefitinib is currently underway to identify the targets and mechanisms of response and resistance to therapy. Results from the 480 samples collected from patients enrolled in this study will be provided in a separate report. Exploratory analysis of tumor biopsies taken from patients in the IDEAL 1 and 2 trials used a reproducible immunohistochemical assay to estimate the correlation of EGFR membrane staining intensity (no, weak, moderate, or strong staining $[0,1+, 2+, 3+$, respectively]) with the probability of objective tumor response or symptom improvement, with the null hypothesis that membrane staining intensity is not predictive of clinical outcome $[33,34]$. The mean proportion of cells staining $2+$ or $3+$ was $31.3 \%$ for patients with response and $37.5 \%$ 
for those without response. Furthermore, in both IDEAL trials, five (15\%) of 34 patients had response with less than $10 \%$ detectable staining. The mean percentage with $3+$ staining was $32.1 \%$ for patients with and $22.8 \%$ for patients without symptom improvement. Therefore, the results of this analysis did not reveal a consistent association between EGFR membrane staining and either objective response or symptom improvement.

Although the current INTACT 2 study did not show superior efficacy when gefitinib was added to paclitaxel and carboplatin, the overall safety profile of gefitinib was confirmed. These data contribute to a better understanding of the optimal use of gefitinib as monotherapy in refractory disease and potentially in sequence with chemotherapy for previously untreated patients with NSCLC.

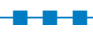

\section{Appendix}

The appendix is included in the full-text version of this article, available on-line at www.jco.org. It is not included in the PDF (via Adobe ${ }^{\circledR}$ Acrobat Reader ${ }^{\circledR}$ ) version.

\section{Authors' Disclosures of Potential Conflicts of Interest}

The following authors or their immediate family members have indicated a financial interest. No conflict exists for drugs or devices used in a study if they are not being evaluated as part of the investigation. Acted as a consultant within the last 2 years: Giuseppe Giaccone, AstraZeneca; Roy S. Herbst, AstraZeneca; Christian Manegold, AstraZeneca; Giorgio Scagliotti, AstraZeneca; Joan Schiller, AstraZeneca; Ronald Natale, AstraZeneca; Vincent Miller, AstraZeneca; David H. Johnson, AstraZeneca. Received more than \$2,000 per year from a company for either of the last 2 years: Ronald Natale, AstraZeneca; Vincent Miller, AstraZeneca.

\section{REFERENCES}

1. Parkin DM, Bray Fl, Devesa SS: Cancer burden in the year 2000: The global picture. Eur J Cancer 37:S4-S66, 2001 (suppl 8)

2. Kelly K, Crowley J, Bunn PA Jr, et al: Randomized phase III trial of paclitaxel plus carboplatin versus vinorelbine plus cisplatin in the treatment of patients with advanced non-smallcell lung cancer: A Southwest Oncology Group trial. J Clin Oncol 19:3210-3218, 2001

3. Schiller $\mathrm{JH}$, Harrington $\mathrm{D}$, Belani $\mathrm{CP}$, et al: Comparison of four chemotherapy regimens for advanced non-small-cell lung cancer. $N$ Engl J Med 346:92-98, 2002

4. Woodburn JR: The epidermal growth factor receptor and its inhibition in cancer therapy. Pharmacol Ther 82:241-250, 1999

5. Nakagawa $K$, Tamura $T$, Negoro $S$, et al: Phase I pharmacokinetic trial of the selective ora epidermal growth factor receptor tyrosine kinase inhibitor gefitinib ('Iressa', ZD1839) in Japanese patients with solid malignant tumours. Ann Oncol 14:922-930, 2003

6. Ranson $M$, Hammond LA, Ferry $D$, et al: ZD1839, a selective oral epidermal growth factor receptor-tyrosine kinase inhibitor, is well tolerated and active in patients with solid, malignant tumors: Results of a phase I trial. J Clin Oncol 20:2240-2250, 2002

7. Herbst RS, Maddox AM, Rothenberg ML, et al: Selective oral epidermal growth factor receptor tyrosine kinase inhibitor ZD1839 is generally well-tolerated and has activity in nonsmall-cell lung cancer and other solid tumors: Results of a phase I trial. J Clin Oncol 20:38153825, 2002

8. Baselga $J$, Rischin $D$, Ranson $M$, et al: Phase I safety, pharmacokinetic, and pharmacodynamic trial of ZD1839, a selective oral epidermal growth factor receptor tyrosine kinase inhibitor, in patients with five selected solid tumor types. J Clin Oncol 20:4292-4302, 2002

9. Fukuoka M, Yano S, Giaccone G, et al: Multi-institutional randomized phase II trial of gefitinib for previously treated patients with ad- vanced non-small-cell lung cancer. J Clin Oncol 21:2237-2246, 2003

10. Natale RB, Skarin A, Maddox A-M, et al: Improvement in symptoms and quality of life for advanced non-small-cell lung cancer patients receiving ZD1839 ('Iressa') in IDEAL 2. Proc Am Soc Clin Oncol 21:292a, 2002 (abstr 1167)

11. Kris MG, Natale RB, Herbst RS, et al: Efficacy of gefitinib, an inhibitor of the epidermal growth factor receptor tyrosine kinase, in symptomatic patients with non-small cell lung cancer: A randomized trial. JAMA 290:21492158, 2003

12. Massarelli E, Andre F, Liu DD, et al: A retrospective analysis of the outcome of patients who have received two prior chemotherapy regimens including platinum and docetaxel for recurrent non-small-cell lung cancer. Lung Cancer 39:55-61, 2003

13. Ciardiello F, Caputo R, Bianco R, et al: Antitumor effect and potentiation of cytotoxic drugs activity in human cancer cells by ZD-1839 (Iressa), an epidermal growth factor receptorselective tyrosine kinase inhibitor. Clin Cancer Res 6:2053-2063, 2000

14. Sirotnak FM, Zakowski MF, Miller VA, et al: Efficacy of cytotoxic agents against human tumor xenografts is markedly enhanced by coadministration of ZD1839 (Iressa), an inhibitor of EGFR tyrosine kinase. Clin Cancer Res 6:48854892, 2000

15. Miller VA, Johnson $D H$, Krug $L M$, et al: Pilot trial of the epidermal growth factor receptor tyrosine kinase inhibitor gefitinib plus carboplatin and paclitaxel in patients with stage IIIB or IV non-small-cell lung cancer. J Clin Oncol 21:20942100, 2003

16. Giaccone G, Herbst RS, Manegold C, et al: Phase III clinical trial of gefitinib, an epidermal growth factor receptor inhibitor, in combination with gemcitibine and cisplatin in advanced nonsmall-cell lung cancer: INTACT 1. J Clin Oncol 22:777-784, 2004

17. World Medical Association Declaration of Helsinki. Recommendations guiding physicians in biomedical research involving human subjects. JAMA 277:925-926, 1997

18. van Warmerdam LJ, Rodenhuis $S$, Ten Bokkel Huinink WW, et al: The use of the Calvert formula to determine the optimal carboplatin dosage. J Cancer Res Clin Oncol 121:478-486, 1995

19. Rom DM, Costello RJ, Connell LT: On closed test procedures for dose-response analysis. Stat Med 13:1583-1596, 1994

20. Therasse P, Arbuck SG, Eisenhauer EA, et al: New guidelines to evaluate the response to treatment in solid tumors. J Natl Cancer Inst 92:205-216, 2000

21. Goldman CK, Kim J, Wong WL, et al: Epidermal growth factor stimulates vascular endothelial growth factor production by human malignant glioma cells: A model of glioblastoma multiforme pathophysiology. Mol Biol Cell 4:121133, 1993

22. Ravindranath $N$, Wion $D$, Brachet $P$, et al: Epidermal growth factor modulates the expression of vascular endothelial growth factor in the human prostate. J Androl 22:432-443, 2001

23. Kataki $A$, Scheid $P$, Piet $M$, et al: Tumor infiltrating lymphocytes and macrophages have a potential dual role in lung cancer by supporting both host-defense and tumor progression. J Lab Clin Med 140:320-328, 2002

24. Morikawa K, Walker SM, Nakajima M, et al: Influence of organ environment on the growth, selection, and metastasis of human coIon carcinoma cells in nude mice. Cancer Res 48:6863-6871, 1988

25. Inoue $A$, Saijo $Y$, Maemondo $M$, et al: Severe acute interstitial pneumonia and gefitinib. Lancet 361:137-139, 2003

26. Nicholson RI, Gee JMW, Harper ME: EGFR and cancer prognosis. Eur J Cancer 37:S915, 2001 (suppl 4)

27. Arteaga CL: Epidermal growth factor receptor dependence in human tumors: More than just expression? Oncologist 7:31-39, 2002 (supp 4)

28. Meye A, Fiedler U, Kunert K, et al: Growth inhibitory effects of ZD1839 ('Iressa') on human 
bladder cancer cell lines. Proc Am Assoc Cancer Res 42:805, 2001 (abstr 4320)

29. Moasser MM, Basso A, Averbuch SD, et al: The tyrosine kinase inhibitor ZD1839 ("Iressa") inhibits HER2-driven signaling and suppresses the growth of HER2-overexpressing tumor cells. Cancer Res 61:7184-7188, 2001

30. Janmaat $M L$, Kruyt FAE, Rodriquez JA, et al: Inhibition of the epidermal growth factor receptor induces apoptosis in A431 cells, but not in non-small-cell lung cancer cell lines. Proc
Am Assoc Cancer Res 43:XX, 2002 (abstr 3901)

31. Budillon A, Guarrasi R, Di Gennaro E, et al: ZD1839 ('Iressa'), an EGFR tyrosine kinase inhibitor, potentiates non-Mhc restricted cytotoxicity in human cancer cell lines. Proc Am Assoc Cancer Res 42:XX, 2001 (abstr 4306)

32. Slamon DJ, Leyland-Jones B, Shak S, et al: Use of chemotherapy plus a monoclonal antibody against HER2 for metastatic breast cancer that overexpresses HER2. N Engl J Med 344: 783-792, 2001
33. Janas MS, Franklin WA, Schmidt $K$, et al: Interobserver reproducibility of visually interpreted EGFR immunohistochemical staining in non-small-cell lung cancer. Proc Am Assoc Cancer Res 44:XX, 2003 (abstr LB-213)

34. Bailey LR, Kris M, Wolf $M$, et al: Tumor EGFR membrane staining is not clinically relevant for predicting response in patients receiving gefitinib ('Iressa', ZD1839) monotherapy for pretreated advanced non-small-cell lung cancer IDEAL 1 and 2. Proc Am Assoc Cancer Res 44:1362, 2003 (abstr LB-170) 